\title{
WAVE INDUCED CURRENT MONITORING USING UAV-BASED PHOTOGRAMMETRY
}

\author{
Bumshick Shin, Catholic Kwandong University, sbs114@cku.ac.kr \\ Kyu-Han Kim, Catholic Kwandong University, khkim@cku.ac.kr
}

\begin{abstract}
INTRODUCTION
In recent years, due to the development of hardware and video image processing technology, image analysis technique using a wide coastal coastline, it made it possible to analyze the wave runup and swash, current and so on.

However, in order to obtain the image information of a large area requires a high-resolution imaging at a high position, however, to the recording technique used in the past, there is a limit of height and resolution. Thus, recently, on the basis of remote sensing techniques, or build spatial information technology using UAV (Unmanned Aerial Vehicle) system, and the research and utilization in various fields it increased.

Small UAV platforms is becoming low-cost, miniaturized hyperspectral imaging technology. The direct measurement of wave induce current is tested using image analysis techniques using sea dye maker and UAV. Specially, rip currents are approximately shore normal seaward flows which are strong, localized and rather narrow. In this method, UAV at a region with frequent wave induced current occurrence, and images are continuously obtained in real time. This research investigates the development of wave induced currents using images in East coast of Korea.
\end{abstract}

\section{METHOD}

In this study sediment transport in the major external wave induced current to the direct observation of advection diffusion dye to trace a direct approach was adopted, study area on the maritime distress for the sea dye maker. In the and vertical takeoff and landing is possible to narrow the space available and taking off and landing from the air hovering fight and shooting is possible rotorcraft UAV the use of the orthophoto production after wave induced current phenomenon was identified. Shooting was conducted by routing, takeoff, shooting order.

Using the low-altitude high-resolution image data obtained after completion of the flight in order to produce the orthophoto and DSM (Digital Surface Model) can be modeled high-resolution orthophoto and detailed DSM and model body and correction of the picture also built their own it is easy to handle UAV image processing were performed, it was carried unmanned aerial photo image processing operations, and modeling the data acquired. After the shooting order of processing is divided into picture elements using an external expression of the video shoot junction, GCP matching, photo location optimization step of separating the dye diffusion range and interpretation.

\section{RESULTS}

Since rip currents are developed by longshore currents, the observed longshore current variations in space and time can be used to detect rip current generation. Rip current recorded by UAV when the significant wave heights was $1,9 \mathrm{~m}$ and the period was $6.0 \mathrm{sec}$. The average velocity was $25 \mathrm{~cm} / \mathrm{s}$. These remote sensing observations provide a more synoptic picture of the rip current flow field and allow the identification of several rip events that were not captured by the in situ sensors and times of alongshore deflection of the rip flow outside the surf zone. This study was conducted as part of the preliminary research for developing a method that can precisely measure the trend and velocity of wave induced current. Quantitative estimation of wave induced current is also conducted by using average and variance image of wave induced current area. These efforts will contribute to reduce the hazards of swimmers and shoreline changes by prediction and warning of rip current generation.
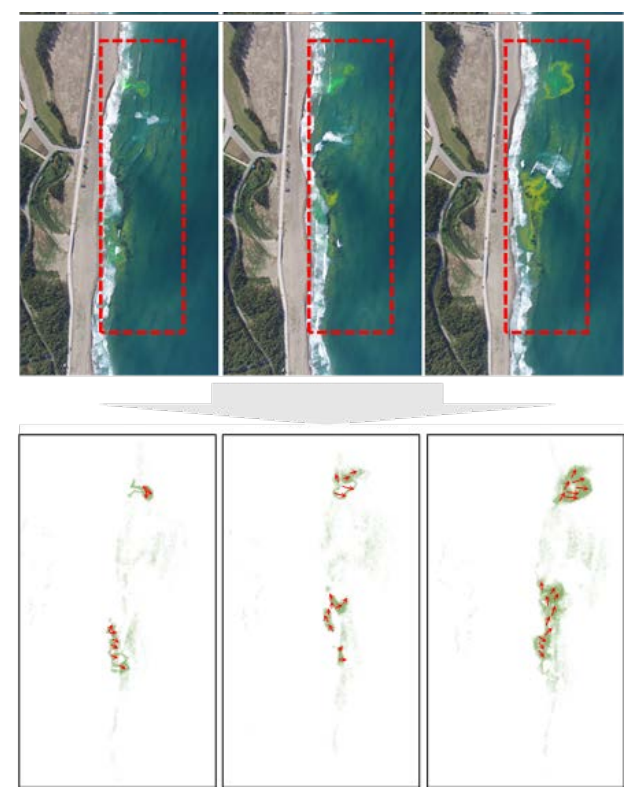

Figure 1 Results of Image analysis

\section{REFERENCES}

Holland, K. T., Holman, R. A., and Sallenger, A. H. (1991): Estimation of overwash bore velocities using video techniques, Proceedings, Coastal Sediments '91. American Society of Civil Engineers, pp. 489-497.

Holland, K. T., and Holman, R. A. (1996): Field observations of beach cusps and swash motions, Marine Geology 134, pp. 77-93.

Mancini, F, Dubbini, M, Gattelli, M, Stecchi, F, Fabbri, SandGabbianelli, G (2013): Using Unmanned Aerial Vehicles (UAV) for High-Resolution Reconstruction of Topography, The Structure from Motion Approach on Coastal Environments, Journal of Remote Sensing, Vol. 5(12), pp. 6680-6898.

Christopher D Drummond1;Mitchell D Harley1;Ian L Turner1A Nashwan A Matheen1;William C Glamore, (2015): UAV Applications to Coastal Engineering, Australasian Coasts \& Ports Conference 